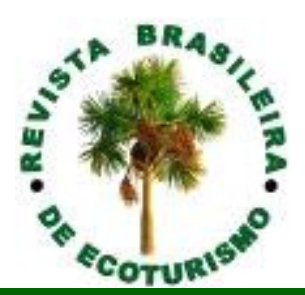

\title{
O Trem da Vale (MG) sob a ótica de ferroviários aposentados, a partir de uma análise linguística do discurso
}

\section{The "Trem da Vale" (MG, Brazil) from the perspective of retired railway workers, from a linguistic analysis of the speech}

\author{
Edwaldo Sérgio dos Anjos
}

\begin{abstract}
RESUMO
O objetivo deste artigo é investigar, a partir do discurso de ferroviários aposentados, como o trabalho ferroviário é concebido por parte desses indivíduos, para, em seguida, desencadear uma reflexão acerca de como eles concebem o Trem da Vale, trem turístico inaugurado em 2006. Esta pesquisa se pauta em dois procedimentos metodológicos, a saber: uma revisão bibliográfica concernente, principalmente, ao labor ferroviário e à seleção das categorias tema, figura, principais ideias combatidas e ideias defendidas, oriundas da Análise Linguística do Discurso. O corpus escolhido é constituído de treze entrevistas, que foram registradas nas cidades mineiras de Ouro Preto e Mariana, no ano de 2007 e, preliminarmente, é possível constatar que, embora os ferroviários tenham um discurso crítico quanto às condições do trabalho na ferrovia, sentem saudade daquele tempo. Além disso, não há, para eles, unanimidade quanto às vantagens e benefícios do Trem da Vale.
\end{abstract}

PALAVRAS-CHAVE: Trabalho Ferroviário; Trabalhador Ferroviário; Trem da Vale (MG); Turismo.

\section{ABSTRACT}

The objective of this paper is to investigate, from the speech of retired railway workers, how the railway work is seen by these individuals, to then, understand how they conceive the Trem da Vale (MG, Brazil), a touristic train created in 2006. This research uses two methodological procedures, namely: a literature review concerning mainly about the railway labor and the selection of theme categories, figure, main discordant ideas and defended ideas, which come from the Linguistic Analysis of Speech. The chosen corpus consists of thirteen interviews, that were recorded in the cities of Ouro Preto and Mariana (MG), in 2007 and, preliminarily, it is possible to note that, although the railway workers have a critical discourse regarding the conditions of work on the railroad, they miss that time.Besides, there isn't, to them, unanimity as to the advantages and benefits of the Trem da Vale.

KEYWORDS: Railway Work; Railway Worker; Trem da Vale; Tourism. 


\section{Introdução}

Existe, no Brasil, certa marginalização do trabalhador ferroviário, consequentemente, de seus ofícios, práticas e representações quando se traz à tona o debate acerca de trens com fins turísticos, iniciativas estas que têm contado com grande interesse no país (PALHARES, 2002; TOMELIN, 2009). Ainda que em uma fase preliminar de pesquisa, Anjos $(2009,2010)$ tem identificado que os sítios eletrônicos associados à divulgação desses trens turísticos ${ }^{1}$ no Brasil são perpassados mais pela ênfase nas locomotivas, estações e paisagens ao redor das linhas férreas do que nos ofícios dos trabalhadores, entendidos, por esse mesmo pesquisador, como elementos constituintes e fundamentais do próprio patrimônio a ser revalorizado por esses projetos turísticos.

A despeito desse relativo desinteresse do setor de trens turísticos pelos ofícios ferroviários, o labor ferroviário no país parece vivenciar um momento bastante singular. $\mathrm{O}$ processo de desestatização da malha ferroviária nacional, ocorrida a partir de 1995 (TOMELIN, 2009), desencadeou, dentre outras consequências, não só a reestruturação do setor, acarretando a quase completa supressão do transporte ferroviário de passageiros no país, mas também um processo de "extinção de antigas funções ferroviárias" (ZAMBELLO, 2005, p.330). Todavia, nesse momento, emerge um conjunto de iniciativas destinadas ao resgate da memória de ferroviários aposentados e da ferrovia, como as pesquisas empreendidas por Segnini (1982), Zambello (2005) e Lima (2009), que vêm se debruçando na tarefa de reconstruir historicamente a trajetória, o modus vivendi e os desafios concernentes ao trabalho ferroviário no Brasil.

Realizadas essas considerações, o objetivo deste artigo é investigar, a partir do discurso de trabalhadores ferroviários aposentados, como o trabalho ferroviário é concebido por parte desses indivíduos, para, em seguida, desencadear a reflexão acerca de como eles, protagonistas do período áureo da ferrovia no Brasil, concebem o Trem da Vale, trem turístico inaugurado em 2006, cujo percurso de $18 \mathrm{~km}$ liga as cidades mineiras de Ouro Preto e Mariana.

O intuito de realizar um estudo do discurso de antigos trabalhadores da ferrovia se justifica, em primeiro lugar, porque parece haver um silenciamento do discurso da classe ferroviária em iniciativas e estudos recentes sobre a relação turismo-ferrovia no Brasil. Um exemplo digno de nota e capaz de corroborar a nossa tese pode ser encontrado na obra Transportes turísticos, de Palhares (2002), que, ao se lançar luz sobre o modal ferroviário, dá pouca atenção a questões relativas a esses funcionários. Ademais, nossa perspectiva vai ao encontro da tese de que, "diante da decadência ferroviária, a memória do antigo trabalhador transmite a experiência do passado, nos possibilita[ndo] compreender as suas mudanças e contradições" (ZAMBELLO, 2005, p.330), sendo isso duplamente verdade no caso do turismo, que, no Brasil, tem se feito valer da malha ferroviária existente eivando-a de nostalgia, para o fomento de trens turístico-culturais. Ou seja, esses relatos tornam-se um rico manancial para análises acerca de como o trabalho ferroviário era concebido, não sob a lógica oficial ou das companhias, mas sob o prisma desses próprios 
profissionais, permitindo que, ao se conhecer esses pontos de vista, as visitas a trens turísticos possam, quem sabe, fomentar a dilatação da compreensão dos visitantes acerca da ferrovia, inclusive os conflitos, dificuldades e particularidades concernentes a esse modal ${ }^{2}$.

Posto isso, parece ser interessante visualizar o atrativo turístico Trem da Vale não apenas sob a ótica dos turistas, ou ainda dos empresários ligados ao empreendimento, mas por que não lançar luz sobre o Trem da Vale sob o prisma dos trabalhadores da ferrovia, que, inclusive, operavam ao longo de todo o trecho em que hoje o trem se situa? Outra questão que tende a justificar este paper é que a nossa investigação, ao se fazer valer de categorias analíticas oriundas da Análise do Discurso (AD), tende a trazer uma conotação inédita às análises sobre o trabalho ferroviário sob a perspectiva dos próprios colaboradores, pois analisa seus discursos de posse do instrumental metodológico fornecido pela $A D$, algo inusitado nos estudos do tema.

Quanto às estratégias metodológicas, um primeiro procedimento metodológico em que este trabalho se pauta diz respeito a uma revisão de literatura, pautada principalmente na questão do trabalhador da linha férrea. Visava-se, ao se realizar tal procedimento, não só fundamentar teoricamente a nossa análise, bem como aprofundar a nossa compreensão não só sobre o fenômeno do trabalho, mas apreender considerações específicas do serviço ferroviário, como, por exemplo, os ofícios existentes. Para tanto, selecionamos, para problematizar a temática do labor ferroviário, Segnini (1982), que investiga os dispositivos disciplinares adotados pela Companhia Paulista de Estradas de Ferro para enquadrar os trabalhadores da organização. Outra contribuição enriquecedora é a dissertação de Zambello (2005), cujo objetivo é resgatar as representações sociais de ferroviários vinculados à Estrada de Ferro Mogyana e à Estrada de Ferro Paulista. Por último, salienta-se o aporte de Lima (2009), que lança seu olhar sobre como a ferrovia em Minas Gerais, no período compreendido entre 1850 e 1930, carregava consigo difíceis condições de trabalho ${ }^{3}$.

A segunda estratégia metodológica contemplada diz respeito à seleção e, consequentemente, eleição de dados critérios linguísticos do discurso como categorias de análise do corpus ${ }^{4}$, que é constituído de treze entrevistas realizadas a partir da metodologia de história oral, coletadas e registradas nas cidades mineiras de Ouro Preto e Mariana, no ano de 2007. Esses registros foram realizados pela equipe de Memória Oral d'O Santa Rosa Bureau ${ }^{5}$ e fazem parte das ações ligadas ao Vale Registrar 6 , programa de natureza historiográfica vinculado ao Trem da Vale, locomotiva turística inaugurada e operada, a partir de 2006, pela Ferrovia Centro Atlântica e que liga, mediante um trecho de $18 \mathrm{~km}$, a primeira capital de Minas Gerais a Ouro Preto.

Quanto aos critérios linguísticos, ao invés de selecioná-los aleatoriamente, optou-se, em primeiro lugar, pela concepção de uma pergunta-problema, capaz de sistematizar a questão alvo desta investigação, tal como descrita a seguir: "Quais as visões desses trabalhadores ferroviários aposentados, ligados a Ouro Preto e Mariana, sobre suas experiências profissionais?". E, a partir desta indagação, uma 
segunda questão se apresenta: "Como esses indivíduos, marcados pelas suas experiências profissionais pretéritas, visualizam o Trem da Vale?".

Assim, com vistas a não só ordenar a enorme gama de dados existentes nas treze entrevistas aqui analisadas, mas também identificar critérios capazes mais úteis para responder à primeira indagação supracitada, optou-se, antes de mais nada, por analisar os textos, buscando, inicialmente, identificar os seguintes critérios linguísticos presentes nas entrevistas: os principais temas, entendidos como os elementos semânticos capazes de designar algo abstrato, atuando como categoria ordenadora do mundo natural (FIORIN, 2009; VIANA, 2009) e figuras, tidas como um elemento do plano do discurso que remete a um correspondente concreto no mundo natural (FIORIN, 2009; VIANA, 2009).

Ademais, optou-se também por se contrapor as principais ideias combatidas com as mais relevantes ideias defendidas ao longo dos discursos ${ }^{7}$ dos trabalhadores, buscando identificar como esses aposentados ligados à ferrovia concebem o Trem da Vale.

A opção por se manejar a problemática do trabalho neste artigo se dá pelo fato que a questão profissional figura de maneira proeminente nas entrevistas. $\mathrm{E}$ isso pode ser visualizado diante do fato de que, dentre os diversos percursos semânticos, entendido por Faria (2001a) como a principal categoria para se analisar o intradiscurso e que englobariam, por sua vez, os diferentes percursos temáticos e percursos figurativos ${ }^{8}$ (FARIA, 2001b) existentes no intradiscurso ${ }^{9}$ do corpus, aquele ligado ao trabalho parece ser o mais recorrente. $E$ mais: o trabalho é uma prática social imanente ao turismo, ainda que sob termos nem sempre equânimes (KRIPPENDORF, 2010).

Não obstante, importa considerar, nesse ínterim, que o turismo, ao fomentar, dentre outras questões, o conhecimento de outras realidades culturais, a apreensão de novos saberes, o confronto com outras formas de saberes e fazeres pode maximizar essa vertente educacional ligada ao conhecimento de outras culturas, mormente ao se fazer valer de uma noção de patrimônio mais holística, contemplando também sua feição imaterial (CASTRIOTA, 2009). Mas, por outro lado, não apenas visualizando o patrimônio apenas pelo seu caráter estético, tampouco vê-lo tão só como um recurso (DIAS, 2006), mas também algo dotado de valor político, eivado por uma noção de algo construído socialmente, portanto passível de excluir "parcelas significativas da população, como [...] classes e grupos sociais oprimidos" (DIAS, 2006, p.87).

A estrutura deste trabalho consiste em três partes. A primeira seção será dedicada debater o trabalho ferroviário, como ele se deu no Brasil, que contradições têm apresentado e que aspectos são recorrentes nos estudos relacionados ao tema. O tópico seguinte trará à baila a análise e discussão dos dados, finalizando, à guisa de conclusão, com a exposição das considerações finais desta investigação. 


\title{
O trabalho ferroviário no Brasil: inovações, fases e contradições
}

Esta seção tem como objetivo salientar aspectos relevantes para a compreensão do trabalho ferroviário no Brasil ${ }^{10}$.

Importa considerar, antes de tudo, que o trabalho ferroviário no Brasil pode ser entendido como uma área profissional permeada de ambiguidades desde seu surgimento. Se o setor ferroviário foi, ao longo do século XIX e pelo menos atém meados do século $X X$, identificado como algo moderno, capaz de ilustrar o domínio do homem sobre o tempo e o espaço (VIEIRA, 2010) ou, ainda, como símbolo do progresso (LIMA, 2009), esse imaginário, entretanto, não se reverteu em condições de trabalho dignas. Pelo contrário, ainda que os ferroviários fossem considerados no discurso oficial como "heróis nacionais do progresso" (LIMA, 2009), o serviço ferroviário, mormente as atividades ligadas à construção e manutenção de linhas férreas, esteve comumentemente associado a condições de trabalho precárias. Inclusive, como forma de combater condições trabalhistas adversas, nota-se que os ferroviários foram uma das primeiras categorias profissionais a se organizar enquanto classe, tendo, até mesmo, desencadeado movimentos grevistas ainda no período imperial (VIEIRA, 2010).

Nesse ínterim, a questão das condições subumanas de trabalho nas ferrovias brasileiras é assinalada por Hardman (2005, p.152):

\begin{abstract}
A história dos que fizeram esses caminhos é uma narrativa repleta de mortes, doenças, fugas, motins frustrados e anônimos. Operários de todos os recantos, nesse revolvimento assombroso de terras, igualavam-se por baixo, na condição de escravos modernos, despossuídos e prontos a perecer em holocausto aos senhores do novo maquinismo.
\end{abstract}

Essa temática é ainda retomada por Monteiro (apud VIEIRA, 2010), ao destacar, no final do século XIX, os termos em que se encontravam os 9.000 trabalhadores responsáveis pela construção da ferrovia paranaense ligando o núcleo urbano de Morretes à cidade litorânea de Paranaguá. Ressalta o autor que eles padeciam "com a insalubridade, a fome, as doenças e os acidentes, com o agravante de ser um trabalho executado em desfiladeiros: a vinda do 'progresso' ao Paraná deve ter custado muitas vidas".

Em resumo, é possível considerar uma primeira fase do trabalho ferroviário no Brasil, que se deu até o início do século XX, pautada por condições profissionais pouco dignas, pois, como nos lembra Segnini (1982, p.36), "é através da exploração destes homens [empregados] que a ferrovia cresceu assustadoramente". A situação desses profissionais, principalmente daqueles ligados aos ofícios que exigiam menos qualificação, como, por exemplo, os operários responsáveis por edificar as vias ${ }^{11}$, era quase sempre subumana em diversos locais do país, contrastando radicalmente com o discurso da elite e o discurso oficial que apresentavam o trem como ícone 
do progresso e, por extensão, os trabalhadores como símbolos dessa nova fase desenvolvimentista do país.

Essa contradição do trabalho ferroviário no país se torna ainda mais aguda ao se trazer à tona que o caráter assalariado e não o paradigma escravocrata foi o modelo privilegiado de relações entre trabalhadores e patrões no âmbito ferroviário nacional ainda no século XIX. Isso corrobora a tese quanto às singularidades do trabalho ferroviário, na medida em que foi ele o precursor quanto à instalação do regime livre de relações trabalhistas ao romper formalmente com o paradigma escravocrata. Entretanto, tal fato, para Segnini (1982), permitiu às ferrovias se tornarem "escolas na formação de hábitos de trabalho, melhor dizendo, de uma concepção capitalista de trabalho", visto que "as companhias contratadas para construir as estradas de ferro brasileiras foram, de certo modo, precursoras no emprego de mão de obra assalariada" (ZAMBELLO, 2005, p.51).

Outro ponto digno de nota é que essa situação permaneceu vigente, mesmo com a demanda por funcionários mais bem qualificados, visto que existia, inclusive, em algumas regiões, déficit de mão de obra qualificada (ZAMBELLO, 2005; LIMA 2009). Assim, apesar de ter se intensificado a necessidade pelos trabalhadores imigrantes, já familiarizados com essa modalidade de transporte e com esse tipo de trabalho (LIMA, 2009), eles foram, todavia, considerados como os responsáveis pela "inoculação de ideias exóticas nos trabalhadores brasileiros" (CUNHA, 2000, p.14). Esse fato acabou por fomentar a criação de uma gama de rígidos dispositivos de controle do então nascente setor ferroviário sobre os trabalhadores concernentes a esse modal. Esses aparatos de controle, como códigos disciplinares severos, repressão a greves e punições tinham como intuito não apenas que eles dependessem cada vez mais das companhias ferroviárias (SEGNINI, 1982), mas que suas demandas fossem suprimidas.

Nesse ínterim, é possível referendar as considerações de Segnini (1982, p. 17) ao afirmar que "à medida que adquirem um grau de conscientização maior, com relação ao papel que desempenham nas relações de produção, o conteúdo dos instrumentos utilizados para dominálos se modifica". Foi exatamente o que aconteceu, sobretudo a partir dos anos vinte, que pode ser considerado como o começo de uma segunda fase do trabalho ferroviário no Brasil. Se em um primeiro momento se deu a exploração explícita da maior parte dos profissionais ligados ao trem, e que perdurou até o começo do século $X X$, essa segunda etapa dá lugar a um controle menos explícito, perpassado pelo paternalismo nas relações de produção. (ZAMBELLO, 2005; SEGNINI, 1982).

O paternalismo concernente aos trabalhadores ferroviários é passível de ser visualizado de duas formas. A primeira é fomentada na esfera governamental, quando o Estado tende a esvaziar a autonomia da classe trabalhadora. Segundo essa concepção, caberia ao Estado a função de agente que se sobreporia a um suposto desvio e despreparo das classes sociais (ZAMBELLO, 2005). Por outro lado, coube às empresas, mediante criação de Sociedades Beneficentes, Escola de Aprendizes, construção de Casas para Trabalhadores e outras concessões edificar uma imagem de companhias zelosas que anuiriam com as demandas sindicais, quando, na verdade, dariam continuidade a uma prática que visava o esvaziamento dos 
sindicados, além de favorecer um maior controle sobre a sua mão de obra (SEGNINI, 1982, p.42) ${ }^{12}$.

As condições de trabalho adversas também não resultavam apenas dos ofícios inerentes ao serviço na ferrovia. Pelo contrário, as próprias companhias, ao maximizar ao máximo seus lucros, favoreciam a insatisfação do empregado. No período aqui compreendido, ou seja, nessa segunda fase do trabalho ferroviário no país, que se dá a partir da década de 20 até aproximadamente a década de 60, as companhias de trem brasileiras adotariam, como já mencionado, dispositivos de controle menos explícitos, como o paternalismo nas relações, em que elas criariam um conjunto de instituições ligadas às próprias companhias para oferecer condições mais razoáveis de trabalho. Entretanto, a partir dessa época que, crescentemente, vem à tona a adoção do paradigma da ciência como instrumento de dominação, visto que estava em voga o modelo gerencial pautado na Administração Científica, articulada principalmente por Taylor $\left(\right.$ SEGNINI, 1982) ${ }^{13}$.

Essa pressão crescente da companhia sobre os empregados desencadeou, como consequência, uma sobrecarga ainda maior dos funcionários, haja vista que "[...] as horas descansadas nunca eram suficientes e para prolongar as horas de descanso, o trabalhador tentava enganar a companhia pedindo à esposa para transmitir a falsa informação da ausência do marido quando alguém da escala viesse chamá-los em suas respectivas casas, em horários imprevistos" (ZAMBELLO, 2005, p. 287) ${ }^{14}$. Essa sobrecarga sobre a mão de obra comprometia, em alguns casos, o próprio bem estar dos funcionários, bem como contribuía para a sua crescente insatisfação com as companhias. Esses fatores, aliados à estagnação do setor ferroviário na década de 60 e à má gestão das companhias de trens apressaram aquilo que designaríamos como a terceira fase do trabalho ferroviário no Brasil: a encampação de empresas ferroviárias e, conseguintemente, dos trabalhadores, por entidades estatais. No caso de São Paulo, as empresas privadas de trens foram geridas pela FEPASA, em 1971; e, na maioria do país, pela RFFSA, Rede Ferroviária Federal Sociedade Anônima, a partir do final da década de 50.

Portanto, quando o trabalho ferroviário passa a estar vinculado ao poder público, durante um período de aproximadamente 30, 40 anos, que culminaria com a privatização do setor no final dos anos 90 , eis que o setor passa, gradativamente, a ser marcado pela ineficiência do Estado em sua gestão, não conseguindo mantê-lo competitivo quando em comparação com o modal rodoviário. Isso, para o trabalhador, teve reflexos diretos, pois uma das questões que acometeria, de maneira recorrente, a classe ferroviária no Brasil àquela época diz respeito à ineficiência estatal, também visível nas relações trabalhistas ${ }^{15}$.

Em consequência desses problemas, eis que emerge, como alternativa para sanar os problemas do setor no país, o processo de privatização, efetivado nos anos 90 , que pode ser entendido como a quarta fase do transporte ferroviário no país e, por consequência, do labor ferroviário. Chama a atenção, no entanto, as consequências negativas dessa ação para os trabalhadores, sobretudo o processo de aposentadoria compulsória a que foram submetidos, quase sempre com benefícios muito 
baixos, além de haver um significativo enxugamento do setor, com grande volume de demissões (ZAMBELLO, 2005).

Como se vê, parece ter havido, ao longo da história da ferrovia no país, uma série de conflitos entre trabalhadores e patrões, sobretudo para a garantida de melhores condições de trabalho. A despeito das diferentes fases, o trabalhador ferroviário parece ter vivido poucos momentos de relativa tranquilidade, não apenas sob o prisma econômico, mas também sob a perspectiva legal-jurídica, visto que sua liberdade, em alguns momentos, foi simplesmente tolhida ou seus direitos atenuados. Ou ainda, sob o ponto de vista subjetivo-psicológico, quando se sentiram desmotivados pela ineficiência estatal em gerir as ferrovias no país, preparava-se, ainda, o golpe final na autoestima dessa classe: o processo de desestatização da malha férrea, que praticamente extinguiu a agitada rotina de centenas de estações espalhadas pelo Brasil afora. Feitas essas considerações, passemos agora à análise do discurso das entrevistas advindas do Programa de História Oral, ligado ao Vale Registrar, projeto esse, que, por sua vez, está ligado à implantação do Trem da Vale.

\section{Análise discursiva das entrevistas}

Antes de adentrarmos na análise dos principais temas e figuras presentes no corpus, faz-se necessário considerar que foram escolhidas aleatoriamente treze entrevistas ${ }^{16}$, cujo tema central era a Ferrovia. Chama a atenção que todos os entrevistados são homens, nascidos em Minas Gerais entre 1915 e 1937, se aposentado entre as décadas de 60 e 80. Embora haja registros da entrada desses trabalhadores na Estrada de Ferro Central do Brasil ${ }^{17}$ nos anos 30 , a maior parte dos entrevistados se filiou à companhia na década de 50. Essa entrada, sob o ponto de vista oficial, se deu por intermédio, segundo eles próprios, de um concurso que consistia em operações elementares de matemática, noções de português e conhecimento acerca do ofício que iriam exercer, sobretudo se o cargo era ligado à estação. Contudo, a prestação do concurso se dava, geralmente, após certo de tempo de prática do ofício, normalmente feito nas estações da EFCB após a indicação de algum conhecido ligado ao terminal.

\section{Temas e figuras}

A despeito de o tema trabalho ser o mais recorrente nas entrevistas, como já salientado nesta investigação, é interessante notar que outros percursos semânticos se fazem presentes com alguma relevância ao longo das entrevistas. Importa destacar também a recorrência do percurso semântico da educação englobando o tema da educação profissional, com as figuras, respectivamente, das estações, instituições de ensino profissionalizante, escolas e dos professores. Além disso, chama a atenção o tema do lazer, com as figuras dos encontros, jogos de cartas e passeios, bem como o tema da família com as figuras irmãos e pais.

Aliás, o tema da família descortina nuances interessantes presentes no discurso desses aposentados. Isso porque ele está intimamente associado ao percurso semântico do trabalho, pois, ao elencarmos o tema 
da escolha profissional, correlacionado ao percurso semântico do trabalho, nota-se, claramente, o peso da família na opção pela profissão desses indivíduos. Das treze entrevistas que compõe o corpus, a questão da família como determinante para a escolha da profissão se faz presente em oito textos.

Entretanto, a família e a tradição profissional ligada às gerações predecessoras, elementos reconhecidos por Girard (apud FRIEDMAN; NAVILLE, 1973) como fatores importantes na escolha profissional, não são as únicas causas capazes de influenciar a opção pelo ofício ferroviário. A falta de oportunidades de trabalho em outros setores também é algo presente em diversas entrevistas. É o caso de Dúlio Ferreira que contou não só com a influência da tradição, cujo pai era ferroviário, mas também foi motivado pela ausência de postos de trabalho em outros ramos, assim como Leonel de Oliveira e Heraldo Nonato ${ }^{18}$.

Além disso, chama a atenção, a nosso ver, no tema do transporte ferroviário, a figura recorrente, praticamente exclusiva do período prédesestatização, dos passageiros. Quanto ao tema da viagem, as figuras mais recorrentes são os viajantes com destino à Congonhas, rotulados pelo neologismo de "congonheiros" e o Santuário Bom Jesus dos Homens, na cidade dos doze profetas de Aleijadinho, haja vista que é unânime, no discurso dos entrevistados que o período relativo a festas religiosas na cidade era responsável pelo maior fluxo de passageiros no trem. Nesse ínterim, é possível visualizar como o tema religião, via a figura do Santuário é repetidamente acionada por eles.

Ademais, além dos temas da viagem, família, lazer e da educação, presente nos discursos dos aposentados, um tema caro ao percurso semântico do trabalho vem à tona ao longo das entrevistas: o tema disciplina, que se revela por intermédio das figuras dos códigos disciplinares, punições e regras presentes no universo trabalhista ferroviário. Nesse sentido, as considerações dos ex-funcionários da Estrada de Ferro Central do Brasil tendem a corroborar a tese de que o setor ferroviário, em geral, foi permeado de rígidos dispositivos de controle sobre o trabalhador. Isso fica claro quando o aposentado da Rede José Fernandes Dutra assevera que "o regulamento era duro mesmo" (VALE REGISTRAR, 2010j, p.14), o que nos remete às considerações de Segnini (1982) quanto aos dispositivos disciplinares rígidos vigentes junto a essas organizações.

Quanto às condições trabalhistas, tema ligado ao percurso semântico do trabalho, é possível vislumbrar, como figuras mais recorrentes, a jornada de trabalho, o salário, a moradia e os acidentes. No entanto, considerase oportuno evidenciar que, ao que parece, há no setor ferroviário uma separação que se dá entre os seis setores - inspetoria geral, contadoria, almoxarifado, tráfego, linha e estação - que, em geral, compõe o ramo. Essa linha divisória parece contemplar desde questões simbólicas, como o reconhecimento obtido por dado cargo, perpassando pelas condições de trabalho e culminando no ordenado. Tal seccionamento pode ser apreendido ao considerarmos, segundo o discurso dos entrevistados, que as moradias ofertadas aos funcionários, situadas próximo às estações, além daquelas destinadas aos que pernoitavam na cidade em face de alguma incumbência que assim o exigisse, ficavam à disposição principalmente dos 
empregados de hierarquia mais alta. Para Heraldo Nonato, as casas desses funcionários, como a residência do engenheiro-chefe, eram verdadeiros "palácios" (TREM DA VALE, 2010h, p.11).

Isso parece ficar claro nas entrevistas. Ao passo que profissões como chefes de estação, maquinistas e chefes de trem parecem gozar de maior notoriedade, bem como de salários, atividades braçais ligadas à via permanente, como pedreiros e serventes, parecem representar o oposto do suposto glamour trazido ao se trabalhar no setor. Tal fato se evidencia nas considerações de Benjamin Nicodemos de Oliveira, encarregado, que, após alguns anos, viria a se tornar supervisor de via permanente: "O salário mínimo na região era 3800 , e nós recebíamos 3300 só. E com a família... Eu já estava casado. Lutei muito, com dificuldade! Eu deixava o serviço às quatro horas para pegar biscate até à noite" (VALE REGISTRAR, 2010c, p.12-13). Entretanto, essa situação dos funcionários ligada ao serviço braçal é apresentada sob outra forma pelo maquinista José Gomes Pereira. Para ele, o seu emprego passa a ser visto com um olhar reticente menos pelo ordenado e mais pela jornada de serviço:

[...] Isso aí foi a maior injustiça que pôde acontecer nessa época! A pessoa não tinha assim horário fixo de serviço. Enquanto tivesse serviço, você ia trabalhando, ia trabalhando. Saía daqui com um trem, às vezes, às cinco horas da manhã, viajava o dia inteiro, chegava aqui lá pelas oito, nove horas da noite, descansava um pouquinho e, de manhã cedo, estava outra vez na rotina. Eu trabalhava muito! Era muita injustiça que faziam com a gente, sabe? (TREM DA VALE, 2010l, p.7).

Posto isso, essas condições explicitadas ao longo desta seção tendem a relativizar a noção de uma suposta homogeneidade, consenso e satisfação do "setor ferroviário", que estaria contida menos no campo de sua operação prática, isto é, no dia a dia de trabalho e mais no próprio sintagma que designa esse ramo ou mesmo essa classe profissional. Ou seja, ao invés de se falar em um único setor ferroviário, poder-se-ia pensar em termos mais plurais, isto é, setores ferroviários. Aliás, isso já havia sido identificado, pois "no caso das estradas de ferro, por exemplo, mais do que no das minas, a multiplicidade dos ofícios oferecidos é suficientemente grande para satisfazer a aptidões e inclinações variadas" (GIRARD apud FRIEDMANN; NAVILLE, 1973).

Além disso, ao se rememorar as diferentes fases e ações do setor, sob o prisma dos próprios ferroviários, não são apenas reminiscências positivas, bem como a nostalgia que vêm à tona. Eis um ponto enriquecedor ao trazer à tona o discurso desses ferroviários, na medida em que eles apresentam o seu trabalho permeado de ressalvas, muitas delas bastante particulares. Enfim,

As diversas modalidades de profissões divididas nos espaços das locomotivas, dos vagões, dos carros de passageiros, dos escritórios, das estações e das oficinas e 
ao longo dos trilhos, se constituíram no que as companhias e os sindicatos chamaram de 'família ferroviária', termo que esconde as diferentes experiências de proletarização de homens [...], e [que] dificulta o entendimento da multifacetada cultura ferroviária. É difícil deixar de apontar sentidos generalizáveis à 'categoria' (ZAMBELLO, 2005, p.72).

As condições adversas de trabalho de parte dos ferroviários não se restringem, no entanto, apenas aos trabalhadores ligados à via permanente, isto é, àqueles incumbidos de construir e atuar na manutenção das linhas férreas. Ao que parece, dentre os ferroviários, a função de foguista é tida como talvez o mais sacrificante ofício ferroviário e, consequentemente, vista com menos entusiasmo.

\title{
Principais ideias combatidas com as mais relevantes ideias defendidas
}

Mediante o discurso dos aposentados, a principal ideia defendida por eles é o transporte ferroviário. Tido por eles como organizado, eficiente e "barato", eles são unânimes em assinalar que o modal ainda deveria estar em uso, sobretudo por parte do transporte de passageiros. Por outro lado, a crítica à opção por se privilegiar o modal rodoviário também se repete. No discurso de José João dos Reis, a defesa da linha férrea se faz amparada na concepção de que "todo mundo" achou ruim a desativação da rota ferroviária Ponte Nova - Belo Horizonte, que cruzava pelas duas cidades mineiras. Já para José Fernandes Dutra,

\begin{abstract}
A ferrovia parou porque privatizou. [...] Eu não acredito que vá ficar nisso; para mim, a ferrovia tem que voltar para tudo. O nosso minério que foi transportado por aqui para Vitória... Isso tem que voltar, porque hoje a nossa rodovia virou cemitério. A quantidade de gente que morre ao sábado e domingo é triste, não é? [...] Não tem asfalto que aguenta (VALE REGISTRAR, 2010j, p.37).
\end{abstract}

Nota-se no depoimento supracitado o poder da memória em problematizar sob outros termos o passado. Eis aquilo que nos alerta Pollak (1989) quanto ao fato de que, memórias silenciadas, quando vêm à tona, tendem a trazer horizontes novos em relação aos fatos. Além disso, percebe-se um claro compromisso da memória com a cidadania, nos termos de De Decca (1992), ao asseverar que a memória pode se contrapor à história oficial, contribuindo também para que grupos construam suas identidades a partir também de releituras do pretérito. No caso em questão há um nítido confronto entre um discurso otimista em relação ao modal rodoviário e uma visão pessimista, o associando, inclusive, a mortes.

Outro aspecto correlacionado à defesa do modal ferroviário e à substituição da ferrovia pelo transporte rodoviário se refere a Vale e ao Trem turístico por ela operado. Ao que parece, a visão que os ferroviários 
aposentados possuem da Companhia não é consensual, pois, para Antônio Miguel,

Nós trabalhávamos às vezes conjugados com a Vale. Era Nova Era, Vale do Rio Doce... Isso já teve um punhado de nome! Vale do Rio Doce, Estrada de Ferro Vitória-Minas, isso já mudou muito de nome. Porque, para poder roubar de outro jeito, eles têm que estar mudando o nome. Esta que está aqui agora não é a Vitória-Minas, e nem essa... Como é que vocês dizem aí? Vale do Rio Doce... Rede Ferroviária... Para poder nos prejudicar. Só no meu ordenado eles me deram prejuízo de 300 mil reais, que foram cortados. Esse negócio mudou o nome, RC... RCA, sei lá. Você pergunta: "Ah, é aquele Trem da Vale? É coisa..." Vale o quê? Eles puseram na Rede Ferroviária Federal Sociedade Anônima, para esses negócios aí, Centro Atlântica [inaudível]. Você pergunta e tem dia que isso é Centro-Atlântica; pergunta outro, não, é Vale do Rio Doce (VALE REGISTRAR, 2010b, p.7).

Outras críticas à empresa e ao seu trem turístico continuam encontram eco no ex-telegrafista, que, embora satisfeito com o trem turístico, além de ter comparecido à festa de inauguração, considerou:

No dia eu não estava me sentindo muito bem, para andar e tudo. Mas compareci satisfeito, porque eu achei aquilo uma coisa muito útil - até política - para Ouro Preto e Mariana. Eu considero que deveria ser até Ponte Nova. É um... Parece um descaso, desinteresse dos políticos de lá, das cidades de Raul Soares, Ponte Nova, Caratinga, Rio Casca, por ali. Ou falta de maldade ou descaso. [...] É lamentável que eles não tenham ido até Ponte Nova. Só entre Ouro Preto e Mariana é. [...]. Se levasse o trem até Ponte Nova [inaudível], mas só até Mariana ficou assim um vazio daqueles prefeitos, daquele pessoal de lá, desinteresse deles. Por que não vai levar o trem lá? Por quê? Sem poder basear lá? (VALE REGISTRAR, 2010b, p.29).

A crítica do aposentado perpassa pela noção, ainda presente no imaginário de alguns ex-trabalhadores de que o custo da passagem de trem é acessível. Tal fato se reveste de importância, pois não se liga a uma noção reducionista de turismo, marcada pela mágica, pela idealização (KRIPPENDORF, 2010) e mais compromissada com os anseios e saberes locais. Isso é que justificaria a ampliação da oferta do trem que liga apenas Ouro Preto à Mariana:

O movimento de turismo, de Mariana para Ouro Preto e vice-versa, é um negócio que pode... Eu nem sei o preço que eles cobram [riso] [inaudível]. Mas isso não vai ficar nisso. Para mim a ferrovia vai lá em Vitória por aqui. Eles 
vão reformar isso tudo, porque o transporte mais barato que nós temos é o ferroviário. O transporte rodoviário, com essas carretas com essas toneladas... É excesso de tonelada para um asfaltozinho assim aguentar. Não, não, tem que acabar mesmo. É o que está acontecendo, gente morrendo todo dia, não é? (VALE REGISTRAR, 2010j.p.38).

E ainda,

Porque se viaja ali em maior quantidade. A pessoa que não tem condições, que não tem um carro ou que quer passear no domingo, pessoa mais simples, pega o trem, a passagem é mais barata, vai lá e volta. Foi a Mariana. A pessoa que veio visitar, chega a Ouro Preto, vai até a Estação, passeia até Mariana, de Mariana quer vir a Ouro Preto também. Então, para o turismo realmente foi útil, muito útil. Mas, no todo, deveria ser até Ponte Nova, pelo menos Ponte Nova, com todo o prejuízo que viesse, dia sim, dia não, ou diário, não é? Moralmente seria Ponte Nova o certo, não é? (VALE REGISTRAR, 2010j.p.38).

Entretanto, a opinião de Benjamin Nicomedes sobre o Trem Turístico da Vale é outra:

Graças a Deus, com a proteção divina, com a boa vontade da Vale e de outros setores - eu não sei se tem outro setor incluído... Aí trouxe uma satisfação enorme para a cidade! Não só para a cidade! Pessoas que moram fora gostaram muito dessa promoção. A Vale foi um dos pontos principais nisso aí e ninguém nega, não é? (VALE REGISTRAR, 2010c, p.28).

Dessa maneira, é possível agrupar o discurso dos aposentados em dois grupos, sendo um favorável e outro contrário ao trem. Essa perspectiva contrária chama a atenção, pois tal movimento de oposição pode ter se dado, talvez, pelo não reconhecimento mais expressivo dos saberes e fazeres desses trabalhadores ferroviários aposentados. Além disso, o fato de parte desses ferroviários não legitimar a iniciativa, embora não a invalide, pelo menos distancia o Trem da Vale como algo representativo do patrimônio ferroviário digno de resguardo. Pelo menos, sob a ótica de alguns trabalhadores.

\section{Considerações finais}

O turismo pautado em ferrovias turísticas tem sido comumentemente ligado à nostalgia e à valorização do passado, embora raramente saliente o papel do trabalhador ferroviário. Sendo assim, este artigo teve como proposta analisar como ferroviários aposentados contemplam seus próprios ofícios e como percebem, nos tempos atuais, projeto turístico do Trem da Vale.

Ao se buscar compreender como esses ex-trabalhadores ferroviários, ligados a Ouro Preto e Mariana, concebem suas experiências profissionais, 
observou-se um conjunto de memórias capazes de problematizar o ofício ferroviário que vivenciavam, ao salientarem as condições árduas de trabalho. Tais condições adversas existiram não apenas no momento em que os trabalhadores estiveram vinculados à iniciativa privada, mas se fizeram presentes também ao longo dos anos em que a malha ferroviária mineira esteve sob o controle estatal. Nesse sentido, sob a lógica dos aposentados, não houve alterações significativas em suas rotinas trabalhistas a partir da mudança de gestor. Pelo contrário, parece haver, em suas memórias, uma continuidade, perpassada pelas dificuldades e pela desvalorização. Contudo, a despeito dos problemas dessa natureza, percebeu-se um ar de nostalgia nos discursos dos entrevistados, desvelando, assim, grande afeto para com as suas práticas laborais.

Ademais, percebeu-se que esses aposentados, marcados pelas suas experiências profissionais pretéritas, visualizam o Trem da Vale de maneira um tanto quanto reticente, pois que a iniciativa veio na esteira de um conjunto de ações, especialmente públicas, que favoreceram a desvalorização do setor ferroviário no Brasil. Curioso notar também que a memória desses ferroviários exerce uma função de problematizar sob outros termos a história ferroviária no Brasil, carregando consigo uma visão crítica em relação ao Trem da Vale, na medida em que se situa esse projeto dentro de um panorama mais amplo, marcadamente pautado pela marginalização da ferrovia.

Assim, o discurso dos ferroviários serve como um contraponto a uma lógica vigente no turismo eivada de mágica e otimismo. Pelo contrário, para eles, a riqueza do ambiente férreo deveria ser resgatada em toda a sua complexidade, não apenas mediante um projeto turístico de $18 \mathrm{~km}$. Sob outros termos, embora reconheçam pontos positivos no Trem da Vale, chamam a atenção para o fato de o trajeto ser apenas uma parte da rota original, o que nos leva a crer a defesa de um projeto mais amplo, mais enriquecedor.

Por último, o discurso desses ex-trabalhadores nos remete a uma reflexão, que, por sinal, tem sido muito cara ao turismo: o fato de se privilegiar, em muitos projetos, os turistas em detrimento dos anfitriões. Nesse sentido, nota-se nas entrevistas dos aposentados uma significativa preocupação para a extensão do percurso do Trem da Vale. Tal como nos parece essa demanda não tem um caráter apenas nostálgico. Muito mais rico do que se possa parecer a princípio, essa consideração se imiscui em uma lógica que busca resgatar a utilidade do próprio trem. Sob outros termos, a rota que ligaria Ouro Preto à Ponte Nova, não apenas à Mariana, anseio da maior parte do grupo de entrevistados, traria consigo a possibilidade de uso do trem por parte de moradores dessas três cidades, isto é, possibilitaria que esse tipo de transporte servisse, de fato, aos anfitriões, não apenas aos turistas. Até porque, hoje, o trajeto de $18 \mathrm{~km}$, tem viagens apenas nos finais de semana e feriados. Essa constatação tende a reforçar a importância de se estudar os discursos de trabalhadores ligados, ainda que indiretamente, a empreendimentos turísticos, pois se visualiza elementos de memórias outras que, tal como se defende aqui, também fazem parte do patrimônio cultural apresentado, e que, infelizmente, nem sempre são valorizados. 


\section{Referências bibliográficas}

ANJOS, E.S. dos. Os trabalhadores de trens turísticos constituintes do atrativo turístico ou simplesmente anônimos? Estudo semiolinguístico dos sítios eletrônicos do Trem da Vale, Minas Gerais, e do Trem CuritibaParanaguá, Paraná. Anais do VI Seminário da Faculdade de Letras (SEVFALE) da UFMG, 2009, Belo Horizonte.

ANJOS, E.S. dos. Reflexão sobre a ascensão dos Trens no Brasil e o silenciamento dos Trabalhadores Ferroviários a partir da Análise Linguística do Discurso da ABOTTC (Associação Brasileira de Operadores de Trens Turísticos Culturais). In: VI Seminário de Pesquisa do Mercosul, 2010, Caxias do Sul. SEMINTUR (6. : 2010 jul. 09-10 : Caxias do Sul, RS) Anais do VI Seminário de Pesquisa em Turismo do Mercosul, Caxias do Sul, julho de 2010 [recurso eletrônico] /. Caxias do Sul: Universidade de Caxias do Sul, Programa de Pós-Graduação em Turismo ; ed. Pedro de Alcântara, 2010. p. 1-16.

CASTRIOTA, L.B. Patrimônio cultural: conceitos, políticas, instrumentos. São Paulo: Annablume; Belo Horizonte: IEDS, 2009.

CHARAUDEAU, P.; MAINGUENEAU, D. Dicionário de análise do discurso. 2. ed. São Paulo: Contexto, 2008.

CUNHA, L.A. 0 ensino de ofícios nos primórdios da industrialização. São Paulo: UNESP; Brasília, D.F.: FLACSO, 2000.

DE DECCA, E.S. Memória e Cidadania. In: São Paulo (cidade). Secretaria Municipal de Cultura. Departamento do Patrimônio Histórico. $\mathbf{O}$ direito à memória: patrimônio histórico e cidadania. DPH. São Paulo, DPH, 1992, p.129-136.

DIAS, R. Turismo e patrimônio cultural. Recursos que acompanham o crescimento das cidades. São Paulo: Editora Saraiva, 2006.

DUMAZEDIER, J. Trabalho e Lazer. In: FRIEDMANN, G.; NAVILLE, P.; TREANTON, J.R. Tratado de sociologia do trabalho. São Paulo: Cultrix: Ed. Universidade de São Paulo, 1973. Vol.2. Cap.24, p.397-427.

FARIA, A.A.M. . Interdiscurso e intradiscurso: da teoria à metodologia. In: MENDES E.A.M.; BENN-IBLER, V.; OLIVEIRA, P.M. (Org.). O novo milênio: interfaces linguísticas e literárias. Belo Horizonte: Faculdade de Letras da UFMG, 2001a, v. , p. 31-37.

FARIA, A.A M. . Interdiscurso, intradiscurso e leitura: o caso de Germinal. In: MARI, H.; MELLO, R.; MACHADO, I.L. (Org.). Análise do discurso: fundamentos e práticas. Belo Horizonte: Núcleo de Análise do discurso Faculdade de Letras da UFMG, 2001b, v., p. 241-287.

FARIA, A.A.M.. Aspectos de um discurso empresarial. In: CARRIERI, A.P.; SARAIVA, L.A.S.; PIMENTEL, T.D.; SOUZA-RICARDO, P.A.G.. (Org.). Análise do discurso em estudos organizacionais. 1 ed. Curitiba; Belo Horizonte: Juruá Ed.; FAPEMIG + NEOS/FACE/UFMG, 2009, v. único, p. 45-52.

FIORIN, J.L. Linguagem e ideologia. 8. ed. rev. e atual. São Paulo: Ática, 2009. 
FRIEDMANN, G.. O objetivo da Sociologia do Trabalho. In: FRIEDMANN, G.; NAVILLE, P.; TREANTON, J.R. Tratado de sociologia do trabalho. São Paulo: Cultrix: Ed. Universidade de São Paulo, 1973. Vol.1. Cap. 1, p.19-44.

GIRARD, A. Orientação e formação profissionais. In: FRIEDMANN, G.; NAVILLE, P.; TREANTON, J.R. Tratado de sociologia do trabalho. São Paulo: Cultrix: Ed. Universidade de São Paulo, 1973. Vol.1. Cap.5, p.203241.

HARDMAN, F.F. Trem-fantasma: a ferrovia Madeira-Mamoré e a modernidade na selva. 2. ed. rev. e ampl. São Paulo: Companhia das Letras, 2005.

KRIPPENDORF, J.. Sociologia do turismo: para uma nova compreensão do lazer e das viagens. São Paulo: Aleph, 2010.

NAVILLE, P. O Método na Sociologia do Trabalho. In: FRIEDMANN, G.; NAVILLE, P.; TREANTON, J.R. Tratado de sociologia do trabalho. São Paulo: Cultrix: Ed. Universidade de São Paulo, 1973. Vol 1. Cap.2, p.45-78.

LIMA, P.L.O. Ferrovia, sociedade e cultura 1850-1930. Belo Horizonte: Argvmentvm, 2009.

PALHARES, G.L. Transportes turísticos. São Paulo: Aleph, 2002.

POLLAK, M. Memória, esquecimento, silêncio. Estudos Históricos, vol. 2, ํㅡㄴ. 1989.

PROGRAMA DE EDUCAÇÃO PATRIMONIAL - Vale Registrar. 2010a. Núcleo de História Oral. Disponível em: http://www.tremdavale.org/novo/bolt tools/files/pdf/VR-HT-OP-018 AB -

Antonio Andre da Luz-20090722-115200.PDF. Acesso em 20 dez. 2010.

PROGRAMA DE EDUCAÇÃO PATRIMONIAL - Vale Registrar. 2010b. Núcleo de História Oral. Disponível em: http://www.tremdavale.org/novo/bolt tools/files/pdf/VR-HT-OP-001 -

Antonio Miguel Leite-20090722-114030.PDF. Acesso em 20 dez. 2010.

PROGRAMA DE EDUCAÇÃO PATRIMONIAL - Vale Registrar. 2010c. Núcleo de História Oral. Disponível em: http://www.tremdavale.org/novo/bolt tools/files/pdf/VR-HT-MA-009 -

Benajmim Nicomedes de Oliveira-20090722-115251.PDF. Acesso em 20 dez. 2010.

PROGRAMA DE EDUCAÇÃO PATRIMONIAL - Vale Registrar. 2010d. Núcleo de História Oral. Disponível em: http://www.tremdavale.org/novo/bolt tools/files/pdf/OP-002 AB -

Claudino Siqueira Filho-20090706-094019.PDF. Acesso em 20 dez. 2010.

PROGRAMA DE EDUCAÇÃO PATRIMONIAL - Vale Registrar. 2010e. Núcleo de História Oral. Disponível em: http://www.tremdavale.org/novo/bolt tools/files/pdf/VR-HT-OP-011 Duilio Ferreira-20090722-115552.PDF. Acesso em 20 dez. 2010. 
PROGRAMA DE EDUCAÇÃO PATRIMONIAL - Vale Registrar. 2010f. Núcleo de História Oral. Disponível em: http://www.tremdavale.org/novo/bolt tools/files/pdf/MA-002 -

Emilio Fonseca Oliveira-20090722-115715.PDF. Acesso em $20 \mathrm{dez}$. 2010.

PROGRAMA DE EDUCAÇÃO PATRIMONIAL - Vale Registrar. 2010g. Núcleo de História Oral. Disponível em: http://www.tremdavale.org/novo/bolt tools/files/pdf/VR-HT-OP-003 AB -

Fabio Goncalo Baudson-20090722-115858.PDF. Acesso em 20 dez. 2010.

PROGRAMA DE EDUCAÇÃO PATRIMONIAL - Vale Registrar. 2010h. Núcleo de História Oral. Disponível em: http://www.tremdavale.org/novo/bolt tools/files/pdf/OP-003 AB Heraldo Nonato-20090706-101133.PDF. Acesso em 20 dez. 2010.

PROGRAMA DE EDUCAÇÃO PATRIMONIAL - Vale Registrar. 2010i. Núcleo de História Oral. Disponível em: http://www.tremdavale.org/novo/bolt tools/files/pdf/VR-HT-MA-013 Jose Benigno de Souza-20090722-120531.PDF. Acesso em 20 dez. 2010.

PROGRAMA DE EDUCAÇÃO PATRIMONIAL - Vale Registrar. 2010j. Núcleo de História Oral. Disponível em: http://www.tremdavale.org/novo/bolt tools/files/pdf/VR-HT-MA-001 AB Jose Fernandes Dutra-20090722-120829.PDF. Acesso em 20 dez. 2010.

PROGRAMA DE EDUCAÇÃO PATRIMONIAL - Vale Registrar. 2010I. Núcleo de História Oral. Disponível em: http://www.tremdavale.org/novo/bolt tools/files/pdf/VR-HT-MA-007 Jose Gomes Pereira-20090722-120907.PDF. Acesso em 20 dez. 2010.

PROGRAMA DE EDUCAÇÃO PATRIMONIAL - Vale Registrar. 2010m. Núcleo de História Oral. Disponível em: http://www.tremdavale.org/novo/bolt tools/files/pdf/VR-HT-MA-002 Jose Joao dos Reis-20090722-120939.PDF. Acesso em 20 dez. 2010.

PROGRAMA DE EDUCAÇÃO PATRIMONIAL - Vale Registrar. 2010n. Núcleo de História Oral. Disponível em: http://www.tremdavale.org/novo/bolt tools/files/pdf/MA-001 AB Leionel de Oliveira e Souza-20090706-104459.PDF. Acesso em 20 dez. 2010.

SEGNINI, L.R.P. Ferrovia e ferroviários: uma contribuição para a analise do poder disciplinar na empresa. São Paulo: Ed. Autores Associados; Cortez Ed., 1982.

TOMELIN, C.A. Turismo ferroviário. In: PANOSSO NETTO, A.; ANSARAH, M.G.R. Segmentação do mercado turístico: estudos, produtos e perspectivas. Barueri: Manole, 2009. p. 487 - 504.

ZAMBELLO, M.H. Ferrovia e memória: estudo sobre o trabalho e a categoria dos antigos ferroviários da Vila Industrial de Campinas. 2005. Dissertação. Departamento de Sociologia da Faculdade de Filosofia, Letras e Ciências Humanas da Universidade de São Paulo. 


\section{Notas:}

1 Segundo Palhares (2002), os trens turísticos seriam veículos ferroviários destinados exclusivamente ao segmento turístico e que podem ser divididos em duas categorias: trens panorâmicos, que seriam aqueles destinados a viagens cênicas, com foco em elementos paisagísticos, e os trens nostálgicos, que se fazem valer de tecnologias e equipamentos antigos, pouco usuais ao transporte ferroviário regular contemporâneo, cujo foco é o resgate da tradição.

${ }^{2}$ Assim, partimos do pressuposto de que esta investigação se justifica também por trazer à tona o discurso dos trabalhadores sobre seu próprio trabalho, lançando luz sobre o labor ferroviário, com vistas a melhor compreender o próprio modal, fomentando, assim, um turismo ferroviário que, ao contemplar nuances do patrimônio férreo no Brasil, transcenda a ênfase aos bens edificados, como as estações, a via férrea e os trens, pois, acredita-se que o patrimônio ferroviário passível de apreensão e exposição englobaria, também, ofícios, saberes, memórias e práticas de seus trabalhadores, o que corrobora com a tese postulada por diversos autores, como Dias (2006) e Castriota (2009), ao afirmarem que o conceito de patrimônio cultural, na contemporaneidade, passa por um alargamento semântico, contemplando, também, os bens não materiais.

${ }^{3}$ Contudo, a questão das condições de trabalho adversas não parece ter sido uma exclusividade dos trabalhadores ligados à via permanente. Isso fica claro quando Zambello (2005) nos recorda das péssimas condições trabalhistas em que se viam os foguistas, trabalhadores responsáveis por manter o forno das locomotivas à lenha em funcionamento, bem como as extensas jornadas de trabalho dos maquinistas.

${ }^{4}$ Optou-se, de maneira deliberada, em não realizar um estudo exaustivo do corpus mediante um amplo leque de critérios linguísticos previamente selecionados, pois consideramos que seria algo extenso e sem grande proveito analítico, haja vista que apresentaríamos uma lista de dados, um conjunto de resultados, que dificilmente nos levaria a alguma conclusão significativa.

5 O Santa Rosa Bureau Cultural é uma empresa que atua na formatação, planejamento, captação de recursos e gestão de projetos ligados à área cultural. A firma, com sede em Belo Horizonte, Minas Gerais, é corresponsável, junto à Ferrovia Centro Atlântica, pela gestão do Trem da Vale.

${ }^{6}$ Em um recente projeto da Vale, o Vale Registrar, é possível identificar que essa iniciativa, ao se pautar na realização e registro de entrevistas com membros de Ouro Preto e Mariana com reconhecido saber e experiência sobre assuntos como a ferrovia, visaria, mediante o processo de ativação das memórias individuais e coletivas, favorecer que as mesmas não se percam no tempo, podendo ser compartilhadas com a comunidade. Além disso, esses registros serviriam para a composição de um acervo público, capaz, posteriormente, de ser alvo de investigações por parte de interessados (TREM DA VALE, 2009). Segundo dados dessa mesma publicação, foram realizadas, até o final de 2009, 116 entrevistas subdivididas em dois tipos: depoimentos de história de vida (30) e entrevistas temáticas (86), subdividas nos temas de mineração, ferrovia e tecelagem.

7 Segundo Fiorin (2005), citado por Faria (2005, p 257), o discurso é resultado de "um conjunto de temas e figuras que materializa uma dada visão de mundo", conjunto este que, ao ser situado no plano do conteúdo, "[...] precisa unir-se a um plano de expressão para manifestar-se".

8 Segundo Fiorin (2009, p.82), "um encadeamento de temas que podem ser resumidos num tema mais geral", ao passo que o percurso figurativo, nos dizeres 
do próprio autor, pode ser entendido como um "encadeamento de figuras que manifesta um dado tema".

${ }^{9}$ Intradiscuso, nos dizeres de Maingueneau (In CHARAUDEAU e MAINGUENEAU, 2008, p.290), pode ser entendido como o resultado das relações entre os constituintes de um mesmo discurso, ao passo que o interdiscurso se daria mediante "as relações desse discurso com outros discursos". (op. cit.) Já para Lima (2009, p.15) o intradiscurso pode ser compreendido como sendo o texto, nesse caso, como uma manifestação de um plano de conteúdo.

${ }^{10}$ Ao se pensar o trabalho, esta pesquisa se vincula à Friedman (In FRIEDMAN e NAVILLE, 1973), que considera o trabalho como um traço específico da espécie humana, além de compreendê-lo como uma condição elementar da vida em sociedade, e a Girard (In FRIEDMAN e NAVILLE, 1973), quando assinala como a tradição e a família influenciam na decisão por se seguir dada carreira.

11 Grosso modo, as companhias de trens nacionais adotaram a mesma estrutura organizacional das companhias europeias e norte-americanas, o que resultou na criação, no país, de aproximadamente 80 ofícios. Essas empresas apresentavam, em linhas gerais, seis divisões, a saber: inspetoria geral, contadoria, almoxarifado, tráfego, linha e estação, sendo essa subdividida em escritório, oficinas e tração (ZAMBELLO, 2005).

${ }^{12}$ Outro aspecto passível de menção no que tange ao trabalho ferroviário é a falta de segurança, passível de ser analisada a partir de dois prismas. O primeiro diz respeito ao risco inerente ao próprio serviço; outro viés refere-se à falta de investimentos das companhias para assegurar uma melhor condição de trabalho a seus funcionários.

${ }^{13}$ A proposta trazida pela Administração Científica advoga que a produção deve ser elevada ao nível máximo, sem desperdícios de qualquer natureza, cabendo ao servidor apenas executar as suas tarefas, ficando isento, portanto, de "pensar" sobre sua prática, sua profissão. Essa corrente da administração defendia a tese de um adestramento da mão de obra, concepção substancialmente defendida pelos patrões e companhias à época.

${ }^{14}$ Importa considerar que o setor ferroviário também foi precursor na implantação da educação profissional no país, mormente em São Paulo (CUNHA, 2000).

${ }^{15}$ Embora, para os trabalhadores, o fato de terem se tornado funcionários públicos tenha favorecido a conquista de benefícios, como a estabilidade e melhores condições de segurança, como equipamentos de proteção, até então inexistentes, foram recorrentes, todavia, os seguintes problemas na administração estatal ferroviária: diminuição do número de trabalhadores, extinção de ofícios, visto que o transporte de passageiros era cada vez menos expressivo no modal ferroviário, sucateamento de carros, locomotivas e vagões e menor valorização do saber em detrimento de uma política de cargos mais rígida e com influência política (ZAMBELLO, 2005).

${ }^{16}$ Os entrevistados são: Antônio André da Luz, fiscal de tráfego, auxiliar de estação e chefe de estação; Antônio Miguel Leite, telegrafista; Benjamin Nicodemos de Oliveira, ligado ao setor de obras; Claudino Siqueira Filho, encarregado de turma; Dúlio Ferreira, feitor de turma e supervisor de linha; José Benigno de Souza, guarda-fio; Emílio Fonseca, manobrista e conservador de linha; José Fernandes Dutra, auxiliar de mestre de linha; José João dos Reis, telegrafista; Heraldo Nonato, trabalhador da soca; Fábio Gonçalves Baudison, encarregado de pessoal do setor eletrotécnico; Jordano Vitorino Batisteli, chefe de estação; Leonel de Oliveira e Souza, foguista e maquinista; José Gomes Pereira, maquinista. 
${ }^{17}$ A Estrada de Ferro Central do Brasil (EFCB) foi encampada em 1969, pela Rede Ferroviária Federal S.A através da 6aㅡ Divisão. O Trem da Vale é operado, hoje, em parte do trecho, que partia Belo Horizonte a Ponte Nova, então sob a concessão da EFCB.

${ }^{18}$ No trabalho de Zambello (2005), o historiador, após coletar depoimentos de 33 aposentados das Estrada de Ferro Mogyana e Estrada de Ferro Paulista, elenca que as causas mais comuns para o ingresso na carreira ferroviária junto às companhias foram: i) melhores perspectivas dentre outras oportunidades de trabalho; ii) limitações do mercado de trabalho da cidade de origem; iii) baixo grau de escolaridade; iv) indicação de parentes ou conhecidos que já atuavam junto às companhias.

Edwaldo Sérgio dos Anjos: Universidade Federal de Juiz de Fora, Juiz de Fora, MG, Brasil.

E-mail: edwaldo.anjos@ufjf.edu.br

Link para o currículo Lattes: http://lattes.cnpq.br/8391656015577874

Data de submissão: 31 de maio de 2012

Data de recebimento de correções: 16 de abril de 2014

Data do aceite: 29 de abril de 2014

Avaliado anonimamente 